\title{
Semantic Memory and Language Processing in Aphasia and Dementia
}

\begin{abstract}
Awareness of the theoretical and clinical importance of semantic dementia is itself relatively new to the broad field of neurolinguistics and even newer to the field of adult communication disorders. This fact permits me to speculate that many of us are relatively uninformed, or even that some of us are unaware, of its importance to our practice. Thus, I am thrilled to be able to present to Seminars in Speech and Language readers what I believe is almost a crash course in semantic dementia. Through his careful collection of experts in the disorder who also understand
\end{abstract}

the clinical world, Jamie Reilly has put together a thorough overview of the problem, coupled with practical clinical approaches to its management. The literature reviewed here is current and contemporary, and as knowledge about semantic dementia expands, it can be expected to evolve. Nevertheless, this issue of Seminars will provide readers with a solid theoretical and practical foundation.

$$
\begin{array}{r}
\text { Audrey L. Holland, Ph.D. }{ }^{1} \\
\text { Co-Editor in Chief }
\end{array}
$$

${ }^{1}$ Department of Speech, Hearing and Language Sciences, University of Arizona, Tucson, Arizona.

Semantic Memory and Language Processing in Aphasia and Dementia; Guest Editor, Jamie Reilly, Ph.D.
Semin Speech Lang 2008;29:1-2. Copyright (C) 2008 by Thieme Medical Publishers, Inc., 333 Seventh Avenue, New York, NY 10001, USA. Tel: +1(212) 584-4662. DOI 10.1055/s-2008-1062600. ISSN 0734-0478. 